${ }^{\mathrm{I}}$ Universidade Estadual de Campinas,

Programa de Pós-Graduação em

Antropologia Social, Brasil

lf_sobral@yahoo.com

Luís Felipe Sobral '

\title{
BOGART EM CASABLANCA: \\ AS FORMAS RELIGIOSAS DA VIDA POLÍTICA
}

Vestido com um tuxedo, Rick subiu a escada que dava acesso ao amplo aposento privado no primeiro pavimento de seu bar. Acendeu a luz ao entrar e, antes que pudesse fechar a porta, deparou-se com Ilsa a espreitar a rua através de uma fresta aberta por sua mão na cortina. Virou-se e, do outro extremo do cômodo, encarou-o apreensiva; após fechar a porta, perguntou, entre alguns passos, como ela havia entrado; respondeu que viera pela escada que levava à rua. Mordaz, Rick comentou ter dito que ela voltaria, mas que estava um pouco adiantada; convidou-a a se sentar. "Richard, eu precisava vê-lo", suplicou ansiosa, aproximando-se dele, que, ao ouvir seu nome, exclamou com sarcasmo enquanto punha as mãos nos bolsos: "Estamos de volta a $\mathrm{Pa}$ ris". Questionou ironicamente se tal visita noturna inesperada estaria ligada aos salvo-condutos; com tais documentos, concluiu, ele nunca se sentirá só. Afirmou convicta que, a despeito do preço, precisava deles; replicou fleumático que já havia discutido o assunto com o marido dela: não haveria negócio. Ilsa disse saber como ele se sentia a respeito dela; rogou-lhe a pôr seus sentimentos de lado por algo mais importante. "Terei de ouvir outra vez que grande homem é seu marido, quão importante é a causa pela qual ele luta?" Ela lembrou, com um esboço de sorriso, que também era a causa dele: ao seu modo, Rick lutava pela mesma coisa. "Não luto por mais nada exceto eu mes- 
mo. Sou a única causa pela qual me interesso." Tirou as mãos do bolso, andou até uma das venezianas de madeira que faziam par com as portas envidraçadas de acesso à varanda e a deslocou para dentro. Aflita, acompanhou-o logo em seguida; chamou-o de Richard novamente e apelou ao tempo em que estavam apaixonados, mas ele não deixou que concluísse: "Não mencionaria Paris. É falta de talento para vendas". Ilsa suplicou para que a ouvisse: se soubesse o que de fato acontecera... "Eu não acreditaria. Dirá qualquer coisa para conseguir o que quer". Deu-lhe as costas, dirigiu-se a um móvel no centro do cômodo, abriu e fechou uma cigarreira, buscou o que procurava em outra peça próxima. Ela observou-o por um momento e depois se aproximou; disse que ele queria sentir pena de si mesmo e, não obstante tudo o que estava em jogo, só pensava em seus próprios sentimentos; furiosa e lacrimosa, acusou-o de covarde e fraco. Encarou-a calado. Com um tremor e um gemido, Ilsa desviou os olhos; uma lágrima despencou e disse que sentia muito. Repetiu a desculpa e, passando a mão pela face úmida, recuperou um pouco a força para afirmar que ele era sua última esperança: "Se não nos ajudar, Victor Laszlo morrerá em Casablanca". "E daí?”, replicou Rick, virando-se de lado; "Eu vou morrer em Casablanca. É um bom local para isso". Ilsa observou-o atônita, deu-lhe as costas e se afastou. Ele acendeu um cigarro, exalou uma baforada, iniciou uma frase, tirou o cigarro da boca, voltou-se para ela e se deteve: apontava-lhe um revólver e exigia os salvo-condutos. Rick disse que eles estavam bem ali; com lágrimas prestes a caírem, ela ordenou que os pusesse sobre a mesa; exibindo um leve sorriso de desafio, ele se negou. Ilsa repetiu a ordem. Franzindo o semblante, ele argumentou que, se Laszlo e a causa significavam tanto para ela, nada a deteria; deu alguns passos, acomodando-se à queima-roupa, e disse que facilitaria as coisas para ela; exortou-a a disparar, pois lhe faria um favor. Ilsa abaixou o revólver e, enquanto uma lágrima descia vagarosa, confessou que tentara ficar longe, pensara que nunca o veria novamente e que ele estava fora de sua vida; enfim suspirou e se afastou, dando-lhe as costas novamente. O vinco entre as sobrancelhas de Rick se suavizou; observou-a e deu um passo hesitante; afinal, caminhou devagar até ela e se abraçaram. "No dia em que você deixou Paris", começou ela, afastando a cabeça do ombro dele; completou: "se soubesse o que passei. Se soubesse o quanto te amei, o quanto ainda te amo" - e beijaram-se.

\section{2}

No domingo, 7 de dezembro de I94I, aviões japoneses atacaram Pearl Harbor; no dia seguinte, a peça não encenada Everybody comes to Rick's era submetida à análise na Warner Bros., que avaliaria a possibilidade de produzir um filme. Na quinta-feira seguinte, I I de dezembro, o governo dos Estados Unidos declarava guerra à Alemanha nazista e seus aliados; no mesmo dia, o produtor 
Hal Wallis recebia o relatório encorajando a produção do filme. Quase um ano depois, em 8 de novembro de 1942, os Aliados desembarcaram no Norte da África e tomaram Casablanca; algumas semanas depois, em 26 de novembro, seguindo um conselho do produtor independente David Selznick para lançar o filme imediatamente, a Warner realizava a estreia de Casablanca em Nova York (Friedrich, I989: I40-I45; Schatz, I99I: 3I8). Talvez não haja outro filme hollywoodiano tão intimamente vinculado à guerra, tanto na produção como no conteúdo, como Casablanca. ${ }^{\mathrm{I}} \mathrm{A}$ cena descrita, interpretada por Humphrey Bogart (I899-I957) e Ingrid Bergman (I9I5-I982), ${ }^{2}$ serve de ponto de partida a este artigo, pois concentra de forma dramática a tensão conjuntural entre interesses individuais e constrições sociais, a relação entre proximidade e distância, o entrelaçamento de micro e macro-história, elementos decisivos ao delineamento da persona cinematográfica de Bogart ao longo da guerra.

\section{3}

Diante de um filme inédito estrelado por uma atriz ou um ator já estabelecido na indústria cinematográfica, o público mobilizava o repertório conhecido de personagens do artista e elaborava uma expectativa em certa medida precisa de sua atuação. Através desse cálculo prático destituído de qualquer intelectualismo, a persona artística do intérprete ultrapassava e se sobrepunha à série de seus personagens, de forma que, antes de Ilsa e Rick, trata-se, sobretudo, de Bergman e Bogart. No intuito de compreender esse mecanismo peculiar do cinema hollywoodiano, propenso a privilegiar os personagens de um artista que lhe franquearam o renome e, assim, uma posição estável, é preciso reconstituir as condições históricas de produção e percepção cinematográfica. A noção de persona cinematográfica consiste em um ponto de acesso particularmente conveniente, uma vez que estabelece a mediação entre a imagem artística e a trajetória social do artista; ela é um produto oriundo da relação histórica entre, de um lado, o intérprete e a estrutura de produção, e, de outro, a imagem do intérprete e o público cinematográfico.

Na cena descrita de Casablanca, vê-se que a persona de Bogart se caracteriza por uma marca própria de gênero: sua completa indiferença é revelada, sob circunstâncias extraordinárias, como a aparência rude que esconde sua vulnerabilidade. Não se tratava da primeira vez que tal marca se manifestava na carreira do ator, mas era recentíssima: há pouco mais de um ano mostrara seu valor à Warner, estúdio que o empregava, interpretando, em o falcão maltês, um detetive particular oportunista às voltas com uma relíquia mis teriosa perseguida por aventureiros inescrupulosos. Bogart começara sua carreira na Broadway e passou a fazer filmes na transição do cinema mudo ao falado, em fins dos anos I920; só conseguiu um contrato em Hollywood em I935, onde se especializou em representar coadjuvantes em filmes de 
gângster. Antes da elaboração de uma persona artística, a posição de Bogart no estúdio era frágil; uma vez delineada tal persona, não lhe restava outra opção senão desenvolvê-la, tarefa que, no início da década de I940, passava necessariamente pela obrigação de enfrentar a guerra então em curso. ${ }^{3}$ Dessa forma, Bogart encarnou o líder de um grupo de apostadores que combate uma conspiração nazista em Nova York; em seguida, um militar que impede um ataque japonês no canal do Panamá, simultâneo a Pearl Harbor. ${ }^{4}$

Hollywood (e a Warner, em particular) participou do esforço de guerra de forma explícita. Nas adequações cinematográficas à conjuntura bélica, configurou-se uma relação peculiar entre Hollywood, campo relativamente autônomo de produção cultural, e o governo norte-americano, espaço do poder: se este, ao exigir colaboração no esforço de guerra, exercia domínio político sobre aquele, não determinava a forma específica que seus filmes assumiriam. Hollywood transformou seus produtos para adequá-los a uma demanda externa que advinha do governo, mas o ultrapassava, por consistir em um conflito de proporções globais: daí as variações empreendidas na persona de Bogart, oriundas da lógica estrutural de produção hollywoodiana, que mediava a relação entre as constrições externas ao campo e a prática cinematográfica. Antes de examinar a guinada decisiva na persona do ator que se empreendeu em Casablanca, é necessário descrever o estado do campo cinematográfico hollywoodiano no início da guerra, o que permite, em grande medida, traçar com acuidade seu grau de autonomia diante do campo do poder.

\section{4}

O estado do campo cinematográfico hollywoodiano durante a Segunda Guerra pode ser descrito como o intervalo entre, de um lado, os últimos resquícios da Depressão, e, de outro, os eventos do pós-guerra que transformaram de modo implacável a estrutura da indústria. De modo esquemático, tal intervalo se caracterizou como o apogeu que precedeu a derrocada do sistema de estúdios. ${ }^{5}$ Para compreendê-lo em sua complexidade, é necessário examinar as relações de força externas e internas a Hollywood.

Começo com as forças externas, em particular com os ataques empreendidos pelo Congresso norte-americano à indústria cinematográfica, na passagem da década de 1930 para a de I940, que incluíam acusações de formação de truste, de intervencionismo a favor da guerra (ainda restrita à Europa) e de atividades antiamericanas (Schatz, I997: I3-I4). A campanha antitruste indispunha, de um lado, o Departamento de Justiça, e, de outro, os maiores estúdios e seus esforços de mais de duas décadas para dominar o mercado cinematográfico através de uma estrutura que controlava todas as etapas de produção e distribuição, foco de preocupação do governo, única autoridade capaz de regular tal atividade de escala nacional (Schatz, I997: 
I4-I5). ${ }^{6}$ A disputa antitruste obrigaria os estúdios a se desfazerem de suas salas exibidoras, desfecho judicial decidido apenas no final dos anos 1940 (Schatz, I997: 4); durante a guerra, "o controle de Hollywood sobre cada fase da indústria era agora considerado um recurso-chave, e os filmes, uma fonte ideal de diversão, informação e propaganda tanto para cidadãos como para soldados" (Schatz, I997: 2).7 Entre os isolacionistas, destacaram-se os senadores Burton K. Wheeler e Gerald P. Nye, que acusaram Hollywood de ser uma "máquina de propaganda" sob controle de uma conspiração judaica (Schatz, I997: 38-40); entre os sentinelas que vigiavam as posturas antiamericanas, sobressaiu-se o congressista Martin Dies, que acusou 43 funcionários hollywoodianos - inclusive Bogart - de terem laços com o Partido Comunista (Schatz, I997: 34). Em meados de I940, com a queda da França e a Batalha da Inglaterra, e, um ano mais tarde, com a invasão da União Soviética pela Alemanha nazista - elegendo a primeira como potencial aliada dos Estados Unidos -, tais paranoias conspiratórias perderam força.

De acordo com o Wall Street Journal, em outubro de 1939, de 30 a $35 \%$ da receita hollywoodiana provinha dos mercados de além-mar, perdidos, um após o outro, com a guerra (Schatz, I997: 22-23). Tal situação desequilibrava a estrutura econômica da indústria e aumentava a importância do mercado doméstico, privilegiado com o plano de defesa empreendido pelo governo a partir de 1940 - construção de novas fábricas, reorganização dos horários de trabalho, migração de trabalhadores às cidades, recrutamento e novos acampamentos militares (Schatz, I997: 28) -, uma vez que tal plano "estava centrado em áreas urbano-industriais onde Hollywood fazia a maior parte de seus negócios" (Schatz, I997: 28). O público cinematográfico, por sua vez, crescia rapidamente, pois, por um lado, a economia de guerra aumentou o poder aquisitivo dos norte-americanos, e, por outro, "racionamentos e desabastecimentos generalizados limitavam as opções de como gastar dinheiro. Desse modo, o cinema representava uma forma ideal de recreação e diversão" (Schatz, I99I: 304). ${ }^{8}$ Nesse mesmo período, o público se deparou com uma série de filmes entre os quais o mais notório é ...E o vento levou, responsável "por mais da metade do lucro líquido de Hollywood em I940" (Schatz, I99I: I2) ${ }^{9}$ - cujas produções ambiciosas eram incomparáveis até mesmo com os de maior prestígio. Tal série correspondia a um certo número de produtores independentes ( $\mathrm{Da}$ vid Selznick, Walt Disney, Charlie Chaplin) e indicava que, apesar do controle de produção industrial ainda estar nas mãos dos estúdios, era possível fazer filmes com maior autonomia (Schatz, I99I: II-I3). A busca por autonomia envolvia também a luta das corporações (de atores e atrizes, diretores e escritores) por reconhecimento, já que, até a Depressão, não havia uma organização trabalhista solidamente estabelecida em Hollywood (Schatz, I991: 32).

Assim, da perspectiva hollywoodiana, advinham, oriundas do campo do poder, acusações de intervencionismo a favor da guerra e de antiameri- 
canismo, e um processo antitruste contra o cerne da estrutura de produção cinematográfica; no além-mar, a guerra subtraía os valiosos mercados hollywoodianos, aumentando a importância do mercado doméstico, cujo público crescia devido, em grande medida, à economia de guerra; enfim, no próprio seio do campo cinematográfico, os trabalhadores lutavam por mais autonomia diante dos estúdios. Todas essas ameaças cessaram com a participação decisiva de Hollywood no esforço de guerra; retornaram logo após o término do conflito, e, em conjunto com outras, assinalaram o ocaso do sistema de estúdios. ${ }^{\text {Io }}$

Com a entrada oficial dos Estados Unidos na guerra, em dezembro de I94I, o apoio de Hollywood era comandado pelo Office of War Information (OWI - Serviço de Informação de Guerra), que exercia tanta influência sobre o conteúdo dos filmes, durante o período de guerra, quanto a PCA. Logo após Pearl Harbor, o OWI exigiu que Hollywood se concentrasse em seis assuntos: o inimigo, os aliados, as Forças Armadas, a frente de combate, a vida dos civis durante a guerra e o serviço de aprovisionamento militar. Os estúdios aderiram prontamente (Schatz, I991: 303). ${ }^{11}$

Nessa conjuntura, o índice de autonomia do campo cinematográfico era mínimo em relação ao campo do poder. Ao tomar como objetivo a explicação histórica de um objeto, explicou Michael Baxandall, "nossa tarefa nada mais é que organizar as relações entre uma série de circunstâncias heterogêneas e uma forma complexa no processo de concepção de um projeto" (Baxandall, 2006: 66, grifos do autor). Trata-se, no caso em questão, de descrever a transformação de uma forma singular (a persona de Bogart) por meio da relação triangular entre um objeto (Casablanca), uma tarefa (contribuir para o esforço de guerra) e um conjunto de possibilidades históricas específicas (Baxandall, 2006: 68-69). Ao longo da produção industrial característica do sistema de estúdios, sujeita, como descrito acima, a uma série de elementos incontroláveis, a parte que coube a Bogart - sua performance - foi mínima e, no entanto, decisiva, pois concentrou em sua corporalidade a resultante das relações de força invisíveis aos olhos da câmera e do público. O Bogart que surge na tela, nesse ponto de sua carreira, é mais do que apenas a performance de Bogart como ator: trata-se de sua persona cinematográfica, síntese entre a estrutura hollywoodiana e a conjuntura externa a tal campo de produção.

\section{5}

No verão de 1938, Murray Burnett, professor em uma escola de Nova York, passou férias na Europa acompanhado da esposa: em Viena, testemunharam o horror diante da invasão nazista; no Sul da França, ficaram chocados com o que descreveram como indiferença política e visitaram uma casa noturna que forneceu a ideia para uma peça teatral (Sperber \& Lax, I997: I82). De 
volta à América, Burnett e a amiga Joan Allison escreveram a quatro mãos Everybody comes to Rick's, cujo título se referia tanto ao espaço do drama (a prestigiada casa noturna de Rick) quanto à posição do protagonista, obrigado a tomar uma decisão crucial - a um só tempo, pessoal e política - da qual ninguém, naquele momento, poderia se subtrair (Sperber \& Lax, I997: 182).

Dias depois da ofensiva a Pearl Harbor, a Warner - entre os cinco maiores estúdios hollywoodianos, o mais adaptado à produção industrial durante os anos I930 (Schatz, I99I: 306) ${ }^{12}$ - adquiriu a peça de Burnett e Allison. Durante a guerra, o estúdio executou ajustes radicais em seu sistema: abandonou a fabricação de filmes B e se concentrou no mercado de primeira linha através de unidades de produção, isto é, transferiu a supervisão da responsabilidade de um único produtor central para as mãos de alguns, que se reportavam àquele e controlavam cerca de oito filmes por ano (Schatz, I997: 44-46). Com efeito, "enquanto a produção efetiva permanecia centralizada no estúdio-fábrica e caía sob o controle último da hierarquia executiva, o sistema de unidade claramente acarretava uma dispersão de autoridade administrativa e controle criativo nas fileiras de produtores" (Schatz, I997: 44). Tal estratégia se justificava pelo ataque antitruste então em curso, que fazia objeção à venda de pacotes de filmes - um (ou alguns) de prestígio entre vários de segunda linha - para as salas de cinema, e teve como resultado o corte de metade do volume de filmes produzidos (Schatz, I997: I78).13 Ao mesmo tempo, novas leis tributárias de I94I impunham um pesado ônus aos salários hollywoodianos, encorajando o trabalho free-lance - por vezes com participação nos lucros - e a abertura de companhias próprias de produção (Schatz, I99I: 306). Assim, em fevereiro de I942, Hal Wallis, antigo executivo de produção da casa, assinou um novo contrato que o tornava produtor de unidade: produziria quatro filmes por ano, com liberdade para selecionar o projeto e a equipe, e ainda teria uma porcentagem dos lucros, além de crédito na tela (Sperber \& Lax, I997: I86; Schatz, I99I: 3I8-3I9). Escolheu Everybody comes to Rick's como seu primeiro filme no novo cargo e Bogart para interpretar o protagonista (Sperber \& Lax, I997: 187).

Entretanto, Everybody comes to Rick's não poderia ser filmada imediatamente, pois possuía uma série de elementos inaceitáveis para a PCA, entre os quais o principal era o caráter libertino da protagonista, Lois Meredith, cujo "caso anterior com Rick em Paris acabara com o casamento dele, e ela chega a Casablanca, no início da história, como a amante, não a esposa, de

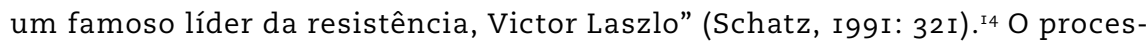
so de transformar a peça no roteiro de Casablanca contou com o esforço sucessivo de vários roteiristas, sem que todos recebessem crédito pelo trabalho: Aeneas Mackenzie e Wally Kline "enriqueceram a história de amor" dos protagonistas e extraíram "os elementos censuráveis", em particular os vinculados a Lois; Casey Robinson, "especialista da casa em melodramas 
românticos", "transformou Lois, a americana libidinosa, em Ilsa, uma jovem europeia cuja família havia sido destruída pelos nazistas e cuja fidelidade a Laszlo e à 'causa' motiva a traição a Rick Blaine e, ao mesmo tempo, a justifica perante ele" (Schatz, I99I: 320-32I). Aos gêmeos Philip e Julius Epstein couberam as reformulações do diálogo da peça e do corrupto chefe de polícia de Casablanca (Schatz, I99I). Finalmente, o ativista liberal Howard Koch substituiu Rick, o advogado expatriado fugindo de um escândalo, por Rick, o idealista magoado e com um passado antifascista escondido (Sperber \& Lax, I997: I89). Contudo, as estruturas narrativas da peça e do filme, de um modo geral, mantiveram-se as mesmas (Sperber \& Lax, I997: 189-190).

\section{6}

Conforme o trabalho avançava, optou-se por uma atriz europeia para o papel de Ilsa; Wallis escolheu a sueca Ingrid Bergman, sob contrato com David Selznick (Schatz, I99I: 320). Ao se tomar a trajetória hollywoodiana de Bergman e, em particular, o imenso esforço realizado pela Warner para destituir Ilsa de qualquer traço maculável de adultério, emerge de modo incisivo a lógica da crença do campo cinematográfico, uma vez que, em fins da década de I940, Bergman, grávida do diretor Roberto Rossellini, expoente do neorrealismo italiano, divorciou-se do marido, Peter Lindstrom, e por isso foi banida de Hollywood (Schatz, I99I: 394-40I). ${ }^{\text {I5 }}$ O desencantamento dos moralistas, choque imenso que alimentou a imprensa sensacionalista, só é compreensível na medida em que se tem em vista a imagem contemporânea da persona da atriz, que "fazia fronteira com o virginal" ${ }^{16}$ : sua atitude herética não calculada deliberadamente como tal - tornou inverossímil o efeito de crença do campo cinematográfico, que sustenta a ilusão de que o artista é sua persona, e escancarou assim a descontinuidade inerente entre eles. O próprio Bogart oferece uma pista inequívoca de tal lógica inscrita no campo de produção hollywoodiano: um pouco depois do término das filmagens de Casablanca, ele comentou a inverossimilhança de seu final, pautado no fato de que "a senhorita Bergman não é o tipo de dama que um homem abriria mão voluntariamente, mesmo em consonância com uma grande quantidade de filosofia altamente expressiva" (Sperber \& Lax, I997: 2I I). ${ }^{\text {17 }}$ De modo inverso, a escolha de Bergman como heroína de Casablanca, além de reforçar as mudanças moralistas executadas no roteiro, impunha mais restrições de mesmo cunho, uma vez que, a despeito das exigências da PCA, o público cinematográfico de 1942 jamais aceitaria traços censuráveis na atriz sueca (Sperber \& Lax, I997: I9I-I92), não apenas por ferir a moral, mas justamente por ser Bergman. Portanto, a persona cinematográfica, ao mesmo tempo em que es tabelecia uma posição social para o artista em Hollywood, tornava-o refém de tal posição. A própria persona do intérprete estabelecido o dominava sim- 
bolicamente por meio da semelhança icônica, sob a qual se encerrava a condição de alteridade: fora das telas, aquele que parecia ser o mesmo era outro.

\section{7}

Na rota de fuga da Europa em guerra, Casablanca, no Marrocos francês, era a porta de saída onde os refugiados deveriam apresentar vistos de trânsito. Com dois alemães assassinados e seus respectivos vistos roubados, a polícia francesa colaboracionista espera capturar o criminoso na casa noturna local - aonde se acorre para realizar todas as espécies de negócio -, cujo proprietário, Rick Blaine, é um cínico expatriado norte-americano que "não arrisca o pescoço por ninguém". Ele carrega uma dolorosa frustração amorosa por Ilsa Lund, que chega em Casablanca acompanhada do marido, Victor Laszlo, líder da resistência, exatamente na noite em que o assassino dos alemães é capturado - não sem antes deixar os vistos com o amargo Rick, que se vê diante da possibilidade de partir com Ilsa, que também o ama, ou garantir a fuga dela com o marido. Escolhe, afinal, a segunda opção.

Se um outro final para Casablanca parece hoje impensável, durante as filmagens a unidade de produção comandada por Wallis não se mostrou tão convicta. Em 25 de maio de I942, as filmagens começaram sem um roteiro concluído, nem um elenco completo definido (Sperber \& Lax, I997: I96-I97). Entre a conclusão conhecida do público atual, chamada pelo roteirista Howard Koch de "o final sacrificial", e o desfecho romântico convencional, no qual Ilsa ficaria com Rick, a inclinação geral apontava para a primeira, mesmo porque a PCA impediria Ilsa de trocar o marido pelo ex-amante; em contrapartida, era preciso encontrar uma justificativa para Ilsa abandonar o homem que amava e uma direção convincente para Rick (Harmetz, 2002: 229). Tal indefinição marcou a produção do filme e, décadas mais tarde, Bergman qualificou a situação de "ridícula" e "horrível": "Todos os dias filmávamos de improviso. Todo dia nos entregavam diálogos e tentávamos pôr algum sentido naquilo. Ninguém sabia o rumo do filme" (Friedrich, I989: I44). Ao enfrentar um tema contemporâneo urgente, a transição geopolítica dos Estados Unidos do isolacionismo ao intervencionismo, a indecisão quanto ao final do filme deixava o flanco ainda mais aberto para que a conjuntura macro-histórica interferisse na micro-história de sua produção.

Dos 75 atores e atrizes de Casablanca, quase todos eram expatriados europeus, entre os quais apenas três imigraram movidos pela possibilidade de uma carreira financeiramente mais atraente: Bergman, o inglês Claude Rains (o corrupto chefe de polícia) e seu conterrâneo Sydney Greenstreet (o oportunista concorrente de Rick). O restante deles buscou refúgio da situação que degringolava na Europa; nem todos eram judeus, porém foram perseguidos de uma forma ou de outra. Alguns poucos, como o austríaco Paul 
Henreid (Laszlo), o alemão Conradt Veidt (o major nazista) e o húngaro Peter Lorre (o ladrão dos vistos), garantiram a posição em Hollywood pelo renome estabelecido em seus países de origem; a maioria nunca ultrapassou a condição de extra: a judia Lotte Palfi, que barganha seus diamantes na casa noturna de Rick, era uma atriz de teatro aspirante na Alemanha até o início das perseguições raciais; o francês Marcel Dalio participara de A grande ilusão e A regra do jogo antes de se tornar o crupiê de Rick; o alemão Curt Bois, que bate carteiras em Casablanca, fora considerado um ator prodígio durante sua infância e encontrara o sucesso nos palcos alemães e em Viena. Tamanha concentração de estrangeiros em um só filme indica, na verdade, a presença em Hollywood de um número ainda maior de artistas refugiados: Igor Stravinski, Bertolt Brecht, Fritz Lang, entre muitos outros (Harmetz, 2002:. 210214). O drama de Rick se expressava através de uma alegoria que traduzia, da perspectiva hollywoodiana, uma crise geopolítica incontornável, explícita na presença maciça de refugiados em Casablanca.

\section{8}

Até aqui, tratei das condições históricas, internas e externas a Hollywood, que franquearam a produção de Casablanca; ainda é preciso explicar como exatamente tal conjuntura interferiu no código cinematográfico. Dessa forma, é possível medir com acuidade, nos termos de Pierre Bourdieu (2005: 249-25I), o índice de refração dos poderes temporais (as exigências governamentais vinculadas à guerra) no campo cinematográfico, isto é, sua autonomia. Em uma palavra, ela era mínima: a retradução hollywoodiana do esforço de guerra resultou em nada menos do que uma mudança, ainda que intermitente, no paradigma narrativo.

Em um sentido mais geral, Casablanca assinalou a conversão do período de guerra do paradigma narrativo clássico de Hollywood. [...] As duas qualidades mais fundamentais da narrativa hollywoodiana, pode-se argumentar, eram (e permanecem) o protagonista orientado para um objetivo individual e a formação do casal. Durante a guerra, entretanto, essas duas qualidades foram radicalmente ajustadas: o indivíduo tinha que se submeter à vontade e atividade do coletivo (a unidade de combate, a comunidade, a nação, a família); e a formação do casal estava suspensa até o fim do conflito, subordinada à especificidade de gênero dos esforços de guerra que envolviam esferas de atividade muito diferentes (e concepções de comportamento heroico) para homens e mulheres (Schatz, I997: 204).

Para Bogart, tal conversão narrativa se mostrou decisiva, pois o eixo de Casablanca não era outro senão a conversão do próprio protagonista. $\mathrm{Na}$ descrição que abre este capítulo, isso é particularmente nítido na postura fleumática de Rick diante do apelo apaixonado de Ilsa, cuja apreensão cresce da ansiedade ao desespero: suas palavras parecem, sucessivamente, chocar- 
-se contra uma indiferença intransponível. Quando o esforço parece se mostrar absolutamente inútil, ela confessa seus próprios sentimentos e o arrasta consigo em sua desolação; ao romper seu fleumatismo, expõe sua vulnerabilidade: Rick não é outro tipo de homem senão o amargo ressentido que sofre pelo amor de uma bela mulher. Assim como em o falcão maltês, no exato momento em que o personagem de Bogart parece estar no controle da situação, esta se inverte e o traço marcante de sua persona é revelado: a mediação dramática entre indiferença e vulnerabilidade. O traço característico de Casablanca repousa na dimensão geopolítica que o personagem de Bogart encerra:

No começo, o Rick Blaine de Bogart é, em grande medida, o herói durão da Warner: cínico e autoconfiante, resmungando repetidamente, "Não arrisco meu pescoço por ninguém". Porém, no curso da história, redescobre sua própria autoestima, junto com seu amor por uma mulher e pelo país. O final heroico de Rick - enviando Ilsa com Laszlo, matando o oficial nazista, e deixando Casablanca para se unir à França Livre - cristalizou a conversão norte-americana da neutralidade ao sacrifício altruísta (Schatz, 1997: 203-204).

Dessa forma, a persona de Bogart sedimentou-se no âmbito cinematográfico; resta saber quais foram as implicações para o ator.

\section{9}

O sucesso de um filme hollywoodiano pode ser medido no esforço de uma produção subsequente em retomar sua estrutura narrativa.$^{18}$ Assim, em Pas sagem para Marselha, Bogart interpretou um jornalista francês liberal que, às vésperas da Segunda Guerra, é perseguido e condenado à prisão na ilha do Diabo, porém escapa e retorna à Europa para lutar; troca o interesse individual pela mulher e o filho que nunca viu pelo dever: morre cumprindo-o e nunca os reencontra. ${ }^{19}$

Em janeiro de 1942, meses antes de começarem as filmagens de Casablanca, Bogart renegociou seu contrato com a Warner, apesar de ainda faltarem dois anos para que o antigo vencesse, sinal da solidez de sua posição (Sperber \& Lax, I997: 192). Ao estúdio não cabia mais o direito de, findado certo intervalo, decidir por uma renovação ou descartá-lo: o novo acordo tinha validade ininterrupta de sete anos, garantia a Bogart pela primeira vez um mês de férias e aumentava seu salário semanal de I.850 para 2.750 dólares (Sperber \& Lax, I997: I92-I93). ${ }^{20} \mathrm{Um}$ dos poucos privilégios ao qual ele não tinha acesso era a aprovação de roteiro; poucos artistas o tinham: apenas as maiores estrelas que souberam negociá-lo, e "Bogart era uma estrela, mas ainda não uma grande" (Sperber \& Lax, I997: 193). Quatro dias antes do início da produção de Casablanca, uma exibição prévia de Across the Pacific, em Washington, convenceu Jack Warner de que Bogart era uma de suas maiores estrelas, o equivalente de Clark Gable - protagonista de ...E o vento levou sob 
contrato com a MGM - no estúdio (Sperber \& Lax, I997: I93). A indicação ao Oscar de melhor ator, em I944, confirmou a análise de Warner por meio do reconhecimento artístico de Bogart. Em Hollywood, na maior parte dos casos, valores artísticos e econômicos se atrelavam: em I943, devido a Casablanca, o nome de Bogart surgia entre as dez maiores estrelas de maior bilheteria do ano (Schatz, I997: 469).

\section{0}

Em ro de fevereiro de I945, o Saturday Evening Post publicou um artigo que iniciava com a seguinte declaração: "Na noite de 6 de novembro de I944, exerci o privilégio concedido pela Constituição dos Estados Unidos e garantido pela Declaração de Direitos. Exprimi minha escolha para a presidência. Bem alto no rádio, disse esperar que F. D. R. [Franklin Delano Roosevelt] fosse eleito" (Bogart, I999: 90-9I).

O autor era Bogart, que emendou, fazendo referência ao mote de Rick em Casablanca: "Assim fazendo, parece, arrisquei meu pescoço" (Bogart, I999: 9I). A figura que se delineia nesse artigo, de acordo com seu autor, é a do artista hollywoodiano como cidadão; não corresponde, portanto, à sua persona cinematográfica. Seriam elas separáveis? A possibilidade de Bogart agir no âmbito da propaganda política em sentido estrito advém justamente do fato de ele ser uma imagem da cultura popular. Isto não significa que o artista e sua persona sejam a mesma coisa; apesar de haver uma contribuição decisiva do trabalho do artista para a elaboração de sua persona, esta é, no limite, um produto coletivo do processo industrial de Hollywood. A relação entre o artista e a persona que se forma na tela ao longo de vários personagens é a de alteridade, que, por meio do efeito de crença do campo cinematográfico, oculta-se na sobreposição do artista pela persona. A eficácia de tal mecanismo consiste em fazer persona e ator compartilharem, por meio da performance, o mesmo substrato, isto é, o próprio corpo do intérprete.

Quando, no verão de I940, o congressista Martin Dies - que "certa vez tentou provar que [a atriz mirim] Shirley Temple era comunista" (Sperber \& Lax, I997: I3I) -, no âmbito de uma investigação de atividades antiamericanas em Hollywood, interrogou Bogart e outros artistas, o ator já possuía, há quatro anos, uma ficha secreta no Federal Bureau of Investigation (FBI), que, "em um informe secreto sobre influência comunista no Screen Actors Guild [sindicato de atores e atrizes], havia - sem base - listado Bogart como um dos vinte e um membros 'com forte inclinação ao Partido Comunista'. Era o primeiro registro do que se tornaria um arquivo do FBI com várias centenas de páginas" (Sperber \& Lax, I997: I30). Uma vez que pautara o inquérito em uma testemunha que se revelou apócrifa, Dies exonerou publicamente alguns dos acusados, entre os quais Bogart, que negara as acusações (Schatz, I997: 34; 
Sklar, I992: I04-I08). De fato, não há evidência de que ele tenha nutrido simpatia pelo comunismo; compreende-se o incidente ao ter em vista que, nesse período de paranoia política nos Estados Unidos, qualquer visão liberal soava como antiamericana para sentinelas reacionárias como Dies. Data desse episódio a conversão política de Bogart, da neutralidade ao ativismo: seis semanas depois, juntou-se à campanha pela reeleição de Roosevelt (Sperber \& Lax, I997: 134). Seguiram-se outras intervenções: em novembro de I943, iniciou um trajeto de dez semanas pela África Ocidental, Norte da África (inclusive Casablanca) e Itália para entreter as tropas norte-americanas (Sperber \& Lax, I997: 226-233); em I944, apoiou a quarta campanha de Roosevelt, como declarado no excerto acima (Sperber \& Lax, I997: 279-282); em I947, integrou o Comitê pela Primeira Emenda - que incluía também John Huston, Katharine Hepburn e Frank Sinatra, entre outros -, em uma missão a Washington de protesto contra a retomada das investigações anticomunistas em Hollywood e sua convocação de dezenove testemunhas (Sperber \& Lax, I997: 354-388; Friedrich, I989: 302-305); enfim, nas eleições presidenciais de I952, apoiou o democrata Adlai Stevenson contra o republicano Dwight Eisenhower (Sperber \& Lax, I997: 466-469). Desse ponto de vista, a conversão política de Rick em Casablanca foi precedida, em alguns anos, pela de Bogart. O interesse de sua principal biógrafa, Ann M. Sperber - que faleceu antes de completar o trabalho, assumido por Eric Lax -, residia na discrepância entre a visão política liberal do ator e o solitário apolítico que ele tantas vezes interpretou (Sperber \& Lax, I997: vii). Nessa observação sagaz emerge a alteridade entre $o$ ator e sua persona.

\section{1}

"Amiúde, tem-se dito que Casablanca toma questões políticas, públicas, e as resolve em um plano individual, pessoal", constatou o historiador Robert Sklar; não apenas, defende, mas também o contrário: "toma questões pessoais e as vincula com [questões] políticas" (Sklar, I992: I4I). Como exatamente se configura a relação entre esses elementos? Ao se examinar o trajeto de Rick do isolacionismo ao intervencionismo, falou-se, do momento de produção de Casablanca até a historiografia recente sobre o filme, em "conversão" e "sacrifício" (Harmetz, 2002: 56-57; Schatz, I99I: 323; Schatz I997: 203-204; Sklar, I992: I4I-I42). Vale a pena considerar o sentido literal de tais termos, especialmente o segundo, que, no caso examinado, engloba o primeiro.

O intérprete de Laszlo, Paul Henreid, "se queixava de que nenhum líder da Resistência desfilaria na Casablanca de Vichy de terno branco" (Friedrich, I989: I44). Não se pode analisar Casablanca na chave do realismo, sob pena de condená-lo por completo à inverossimilhança; faz mais sentido tratá-lo como uma alegoria política cuja narrativa melodramática assume a forma 
sacrificial. ${ }^{21}$ A função de Laszlo não é outra senão a de uma divindade política, um ideal heroico encarnado: puríssimo diante da corrupção do chefe de polícia, do cinismo de Rick, da indecisão de Ilsa; inabalável até mesmo ao compreender que Ilsa e Rick se amam; sua contrapartida é o major nazista, que faz as vezes do mal absoluto. Na intercalação de personagens ambíguos entre símbolos figurados inequívocos, reconhece-se o gênero melodramático, que, "por tradição, abriga e ao mesmo tempo simplifica as questões em pauta na sociedade, trabalhando a experiência dos injustiçados em termos de uma diatribe moral dirigida aos homens de má vontade" (Xavier, 2003: 93) - no caso, Rick em pessoa. Ao operar a troca que assinala sua conversão política, Rick revela a pedagogia moral que é a razão de ser da narrativa melodramática (Brooks, 1985: 5): ele abre mão de seu interesse pessoal (o amor de Ilsa) pela defesa da causa da qual esteve apartado, a luta pela liberdade representada por Laszlo; por meio desse intercâmbio - mediado assim por Ilsa -, recupera o significado de sua vida.

Esse mecanismo corresponde à descrição do sacrifício proposta por Henri Hubert e Marcel Mauss: "ato religioso que mediante a consagração de uma vítima modifica o estado da pessoa moral que o efetua ou de certos objetos pelos quais ela se interessa" (Hubert \& Mauss, 2005: 19, grifos dos autores). Trata-se em particular de um sacrifício pessoal, pois a "personalidade do sacrificante" aquele "que recolhe os benefícios" da operação "ou se submete a seus efeitos", isto é, Rick - "é diretamente afetada" (Hubert \& Mauss, 2005: I6-I9). Por meio do ato de abnegação do protagonista, lembrava-se ao público cinematográfico a presença das forças coletivas que a conjuntura histórica impunha. Se, por um lado, deve-se fazer a ressalva de que Hubert e Mauss examinaram fontes religiosas em sentido estrito, por outro é preciso sublinhar que tinham em mente fenômenos de outra ordem que se mostravam afins ao tema sacrificial, como o "sacrifício pela pátria" que Mauss cita em uma longa carta a Émile Durkheim (Fournier, I994: I62). Sob o triângulo amoroso, vislumbra-se o triângulo sacrificial: entre o primeiro (Rick-Ilsa-Laszlo) e o segundo (sacrificante-vítima-deus), há uma relação de isomorfismo mediada pela força social do compromisso moral; no entanto, enquanto este é propriamente religioso, aquele é inerentemente político.

\section{2}

A formidável tensão entre os domínios político e religioso, tão relevante em Casablanca, faz parte de um fenômeno mais amplo, no espaço e no tempo. Carlo Ginzburg (2009) mostrou como Jacques-Louis David, ao retratar o assassinato de Marat - no momento crítico dos primeiros anos da república francesa vitoriosa sobre a monarquia de direito divino -, combinou elementos clássicos e cristãos, isto é, delineou sua própria legitimidade política 
através da invasão da esfera do sagrado, monopolizada, até então, pela religião. ${ }^{22}$ Tal invasão "seguiu adiante e, sob formas contraditórias, prossegue ainda hoje", afirmou o historiador; completa: "É a outra face da secularização: um fenômeno nascido na Europa e que depois se expandiu pelo mundo, mas que está bem longe de ter vencido a própria batalha. Quando pode, o poder secular se apropria da aura (que é também uma arma) da religião" (Ginzburg, 2009: 2 I3). Continuidade e ruptura se combinam na íntima relação histórica entre secularização e cristianismo, do qual aquela "retomou, mimeticamente, a tendência a se apropriar dos conteúdos e das formas mais variados" (Ginzburg, 2009: 213).

Não é fortuita a relação que se verifica entre o sacrifício patriótico de Rick, a produção de Casablanca, a trajetória de Bogart e o processo histórico mais amplo do nacionalismo. Na tese de Benedict Anderson, o nacionalismo é visto como um artefato cultural no qual a nação é concebida como uma comunidade política imaginada, isto é, uma fraternidade soberana localizada no interior de um território delimitado, e cujos membros estão impedidos de se conhecerem todos devido à ordem numérica elevada, daí a necessidade de instrumentos que permitam imaginar a nação (Anderson, 2008: 31-34). Tal fraternidade é que tornou possível, explica Anderson, que "nestes dois últimos séculos, tantos milhões de pessoas tenham-se não tanto a matar, mas sobretudo a morrer por essas criações imaginárias limitadas" (Anderson, 2008: 34).

Essas mortes nos colocam bruscamente diante do problema central posto pelo nacionalismo: o que faz com que as parcas criações imaginativas da história recente (pouco mais de dois séculos) gerem sacrifícios tão descomunais? Creio que encontraremos os primeiros contornos de uma resposta nas raízes culturais do nacionalismo (Anderson, 2008: 34).

Anderson parte do túmulo do Soldado Desconhecido - o símbolo mais impressionante "da cultura moderna do nacionalismo" (Anderson, 2008: 35), que expressa sua preocupação com a morte e a imortalidade - para indicar que tais raízes se localizam no século XVIII, entre a alvorada do secularismo racionalista e o enfraquecimento do monopólio exercido pela crença religiosa, momento em que a ideia de nação, que encerrava a um só tempo um "passado imemorial" e um "futuro ilimitado", proporcionou "uma transformação secular de fatalidade em continuidade, da contingência em significado" (Anderson, 2008: 35-38). Não se pode pensar o nacionalismo, defende ele, separado dos dois sistemas culturais de onde (e contra os quais) provém: a comunidade religiosa e o reino dinástico (Anderson, 2008: 39). Tampouco dos dois fenômenos setecentistas que floresciam, enquanto aqueles entravam em crise: o romance e o jornal (ou "capitalismo impresso"), mecanismos de representação da simultaneidade em um "tempo vazio e homogêneo", medido pelo relógio e pelo calendário, que, de um lado, opunha-se à temporalida- 
de cristã e dinástica que fazia convergir cosmologia e história, e, de outro, permitia representar a comunidade imaginada, a nação (Anderson, 2008: 5I-70).

Somente ao ter em vista a popularidade absoluta do cinema nas quatro primeiras décadas do século XX é que se pode fazer alguma ideia da força desse tipo de olhar para a nação norte-americana. ${ }^{23}$ Nesse momento, Hollywood detinha uma imensa capacidade de representar a nação, poder exercido pelo capitalismo impresso na fase inicial do processo histórico do nacionalismo descrita por Anderson. Casablanca fornece um exemplo inequívoco. Após fechar seu estabelecimento, na noite do reencontro inesperado com Ilsa, Rick questiona seu amigo pianista: "Sam, se é dezembro de I94I em Casablanca, que horas são em Nova York? Aposto que estão dormindo em Nova York. Aposto que estão dormindo por toda a América". Robert Sklar explica:

Tais falas não se referem às diferenças de fusos horários. Rick está projetando seu próprio torpor político - agora que o reconheceu e começou a despertar dele - sobre sua própria cidade natal, sua nação inteira. Espectadores em I942 e I943 podiam, por sua vez, projetar suas próprias memórias de dezembro de I94I, seus próprios reconhecimentos da realidade da guerra e dos sacrifícios potenciais que ela acarretava, de volta sobre o personagem cinematográfico (Sklar, I992: I4I-I42).

\section{3}

Ao examinar a capacidade da esfera política de entrar em concorrência direta com a ética religiosa, Max Weber cita o exemplo da guerra:

A guerra promove [...] uma comunhão incondicionalmente dedicada e pronta ao sacrifício, entre os combatentes, e libera uma compaixão de massa ativa e um amor pelos que estão sofrendo necessidades. [...] a guerra traz ao guerreiro algo que, em seu significado concreto, é excepcional: faz que ele experimente um significado consagrado da morte, característico apenas da morte na guerra. [...] A morte no campo de batalha difere dessa morte simplesmente inevitável pelo fato de que na guerra, e somente na guerra, o indivíduo pode acreditar que sabe estar morrendo "por" alguma coisa (Weber, I97I: 384 , grifos no original). ${ }^{24}$

Nesse sentido, é notável a frase que abre o texto de contracapa da edição brasileira de Comunidades imaginadas: "Por que sentimos uma emoção quase religiosa diante do túmulo do Soldado Desconhecido?” Atenção ao advérbio "quase": por meio de tal símbolo patriótico do nacionalismo - que representa, em sua anonímia, todos aqueles que morreram pela nação -, opera-se a soberania da esfera política através da apropriação de uma forma religiosa sacrificial, de modo que a estreita proximidade entre os domínios político e religioso não se converta em sobreposição. A Segunda Guerra, evento violento das relações de força externas à nação norte-americana, foi capaz, de forma correspondente, de reorganizar as relações de força internas no sentido de tomar uma posição diante da conjuntura externa; nesse percurso, 
delineou na prática uma experiência de âmbito nacional. A mediação entre os espaços interno e externo foi realizada pelo soldado e por todos aqueles que participaram do esforço de guerra; daí o profundo sentido nacional que o sacrifício de Rick encerrou: ele transformou o paradigma narrativo hollywoodiano, compartilhado por um público de milhões de pessoas, através da urgência do ato político com a força da forma religiosa.

Recebido em I4/03/2013 | Aprovado em 04/02/2014

Luís Felipe Sobral é doutorando em antropologia social pela Universidade Estadual de Campinas (Unicamp) e bolsista da Fundação de Amparo à Pesquisa do Estado de São Paulo (Fapesp). Interessa-se por fenômenos culturais e sociais que ocorreram durante o entreguerras. Publicou, em particular, "O beijo de Spade: gênero, narrativa, cognição" (20II) e "Duas leituras de Malinowski" (2014). 


\section{NOTAS}

I Casablanca, dirigido por Michael Curtiz, produzido por Hal B. Wallis e Jack L. Warner, Warner Bros., I942.

2 A cena descrita possui 3 minutos e 36 segundos e inicia-se à I hora, I9 minutos e 23 segundos de filme.

3 Partindo de uma cena de $O$ falcão maltês (The Maltese falcon, dirigido por John Huston, produzido por Hal B. Wallis e Henry Blanke, Warner Bros., I94I), descrevi (Sobral, 20II) o estabelecimento de Bogart em Hollywood, a elaboração de sua persona cinematográfica e o código de percepção cinematográfica que colocava o público na posição de detetive da narrativa. Tal artigo, assim como este sobre $\mathrm{Ca}$ sablanca, são oriundos de Sobral (20I0).

4 Balas contra a Gestapo (All through the night, dirigido por Vincent Sherman, produzido por Jerry Wald e Hal B. Wallis, Warner Bros., I94I); Garras amarelas (Across the Pacific, dirigido por John Huston e Vincent Sherman, produzido por Jack Saper e Jerry Wald, Warner Bros., I942).

5 O sistema de estúdios consistia na estrutura social, econômica e cultural que, a partir de um processo industrial, controlava e executava todas as etapas da produção de um filme (desde a elaboração do roteiro até sua exibição) e se orientava pelo lucro; do ponto de vista econômico, tratava-se de um oligopólio: cada estúdio se especializou em uma variação do estilo clássico hollywoodiano (os filmes de terror da Universal, os de gângster da Warner etc.) (Schatz, I99I).

6 Os maiores estúdios, em termos de recursos, lançamentos e lucros, eram: MGM, Paramount, 2oth Century-Fox, Warner, RKO, Universal, Columbia e United Artists. As cinco primeiras destacavam-se por serem integradas, isto é, não apenas produziam filmes, mas também possuíam cadeias de salas de cinema por todo o país (Schatz, I997: 47-57).

7 Salvo indicação contrária, todas as traduções são minhas.

8 "Em I940, a indústria cinematográfica mediu sua audiência 'potencial' (incluindo espectadores 'frequentes' e 'ocasionais') em 90-Ioo milhões de uma população total de um pouco mais de I30 milhões" (Schatz, I997: 27). Nesse mesmo ano, o trânsito semanal total nos cinemas norte-americanos era de 80 milhões de pessoas; em 1946, atin- 
giu o ápice, com 90 milhões (U. S. Bureau of the Census, Historical Statistics of the United States, I960, pp. 242-244 apud Schatz, I997: 462).

9 ...E o vento levou (Gone with the wind, dirigido por Victor Fleming, George Cukor e Sam Wood, produzido por David Selznick, Selznick International Pictures \& MGM, 1939). Os eventos do pós-guerra que contribuíram para o ocaso do sistema de estúdios podem ser divididos em dois tipos: de um lado, os domésticos, que incluíam a migração para os subúrbios (longe dos cinemas do centro), o "baby boom", a televisão comercial e outras mudanças nos padrões de consumo; de outro, os de além-mar, cujos mercados fechavam-se à Hollywood devido à Guerra Fria e às medidas protecionistas dos governos europeus (Schatz, I997: 3-4).

I I É preciso lembrar que, em contraste com a Segunda Guerra, a Primeira foi particularmente benéfica para Hollywood, pois, naqueles primeiros anos de organização da prática cinematográfica, as concorrências alemã, italiana, sueca e francesa eram vultuosas; com o conflito, o cinema desses países foi desestruturado, dando espaço para o estabelecimento do domínio hollywoodiano - daí o crítico de cinema Frank Nugent, do The New York Times, observar, em setembro de I939: "Hollywood era um filhote da guerra" (apud Schatz, I997: 22). Sobre a PCA, ver nota I4, abaixo.

I 2 modo de produção da Warner se orientava por uma dupla economia (técnica e narrativa) em consonância com uma rigorosa política financeira que privilegiava a relação custo-benefício: "Renunciando ao brilho e ao glamour da MGM e da Paramount, a Warner optou por uma visão de mundo mais sombria e inóspita" (Schatz, I99I: I47), que a levou a se especializar em filmes de ação masculinos, em particular filmes de gângster (Schatz, I99I: I46-I57).

I3 Em I94I, os oito maiores estúdios hollywoodianos lançaram 379 filmes; em I946, 252 (Film Daily Year Book apud Schatz, I997: 463).

I4 Hollywood era particularmente vulnerável às diversas comissões de censura municipais e estaduais (sociedades religiosas, ligas da virtude, lobbies diversos etc.); para se proteger, estabeleceu um código de autocensura, que entrou em vigor em 1934, sob administração da Production 
Code Administration (PCA), encarregada de avaliar roteiros e filmes para a concessão do selo de aprovação sem o qual um filme não poderia ser exibido. Entre as interdições do código de censura, as mais incisivas se referiam à sexualidade e aos crimes contra a lei (Douin, I998: I55I57, I63-I68).

I5 Os defensores do código de censura "suprimem a alusão ao encontro de Ingrid Bergman e Humphrey Bogart em um bordel parisiense em Casablanca, assim como aquela dos vistos franceses entregues às damas contra certos favores, o leito desfeito em uma cena, e transformam o estatuto da heroína (de casada, torna-se viúva)" (Douin, I998: I65).

I6 A lembrança que o público tinha de Bergman remetia a "uma freira sorridente" em Os sinos de Santa Maria (The bells of Saint Mary's, dirigido e produzido por Leo McCarey, Rainbow Productions, 1945) e Joana d'Arc (Joan of Arc, dirigido por Victor Fleming, produzido por Walter Wanger, Sierra Pictures, 1948) (Friedrich, 1989: 397).

I7 Bogart fala "senhorita", apesar de Bergman estar casada com Lindstrom desde 1937.

I8 Casablanca foi a sexta maior bilheteria de I943, arrecadando 4,I5 milhões de dólares ("All-time film rental champs", Variety, 24, fevereiro de I992, pp. I25-168 apud Schatz, I997: 466). O valor de Casablanca, em particular, é apontado inequivocamente pelo órgão máximo de reconhecimento da indústria cinematográfica, a Academia, que entregou Oscars de direção, filme e roteiro, e indicou o filme para os prêmios de cinematografia, edição, música, ator coadjuvante (Rains) e protagonista: Bogart, sua primeira indicação depois de treze anos e 46 filmes.

I9 Passagem para Marselha (Passage to Marseille, dirigido por Michael Curtiz, produzido por Hal B. Wallis e Jack Warner, Warner, 1944). Além do elenco familiar (Claude Rains, Sydney Greenstreet, Peter Lorre) sob a direção de Curtiz e a produção de Wallis, o próprio trailer faz referência a Casablanca: "No último ano, a Warner Bros. Eletrizou o mundo com Casablanca. Este ano, a Warner Bros. anuncia Passagem para Marselha".

20 Uma estatística de 1939 indica que apenas $6 \%$ dos atores e atrizes hollywoodianos recebiam pelo menos dois mil 
dólares por semana; 79,9 \% recebiam menos de mil dólares semanais e $20, \mathrm{I} \%$, entre mil e dois mil dólares semanais (Rosten, I94I: 344).

2I Isso não significa que realismo e melodrama são, necessariamente, termos excludentes: ver Xavier (2003: 85-86), que também assinalou a urdidura entre alegoria, melodrama e narrativa cristã na formação do cinema hollywoodiano (Xavier, 2003: IOI-I25).

22 Jacques-Louis David, A morte de Marat, I793, óleo sobre tela, I62 X I 28 cm, Musées Royaux des Beaux-Arts, Bruxelas.

23 Com a seguinte convicção é que Robert Sklar abre seu livro sobre a história cultural do cinema norte-americano: "Durante a primeira metade do século XX - de I896 a I946, para ser exato -, os filmes eram o meio cultural mais popular e influente nos Estados Unidos. Eles eram a primeira mídia de massa moderna, e emergiram do fundo à superfície da consciência cultural, recebendo o principal apoio das mais baixas e mais invisíveis classes da sociedade norte-americana" (Sklar, I994: 3).

24 A presença de Weber no final deste ensaio remete à complexa questão sobre o desencantamento do mundo, constituinte do debate que Ginzburg (2009) estabeleceu com T. J. Clark (2007). Ginzburg faz uma crítica bastante discutível: no "mundo desencantado" de Clark e Weber não existiriam contradições genuínas. Não posso explorar essa questão espinhosa, que extrapola os limites deste texto. O que importa assinalar é que, tanto em Casablanca como na representação pictórica do Marat assassinado (analisada por Clark e Ginzburg), a secularização republicana se vê às voltas com uma contradição decisiva: sua força simbólica advém da forma religiosa da qual se apropriou.

\section{REFERÊNCIAS BIBLIOGRÁFICAS}

Anderson, Benedict. (2008). Comunidades imaginadas. Reflexões sobre a origem e a difusão do nacionalismo. São Paulo: Companhia das Letras.

Baxandall, Michael. (2006). Padrões de intenção. A explicação histórica dos quadros. São Paulo: Companhia das Letras.

Bogart, Humphrey. (I999). I stuck my neck out. In: Duchovnay, Gerald. Humphrey Bogart: A bio-bibliography. Westport, Connecticut: Greenwood Press, p. 90-96. 
Bourdieu, Pierre. (2005). As regras da arte. Gênese e estrutura do campo literário. São Paulo: Companhia das Letras. Brooks, Peter. (1985). The melodramatic imagination. Balzac, Henry James, and the mode of excess. Nova York: Columbia University Press.

Clark, T. J. (2007). A pintura do ano II. In: Modernismos. Ensaios sobre política, história e teoria da arte. São Paulo: Cosac Naify, p. 89-I57.

Douin, Jean-Luc. (1998). Dictionnaire de la censure au cinéma. Paris: Presses Universitaires de France.

Duchovnay, Gerald. (I999). Humphrey Bogart: A bio-bibliography. Westport, Connecticut: Greenwood Press.

Fournier, Marcel. (I994). Marcel Mauss. Paris: Fayard. Friedrich, Otto. (I989). A cidade das redes. Hollywood nos anos 1940. São Paulo: Companhia das Letras.

Ginzburg, Carlo. (2009). David, Marat. Arte, política, religião. Serrote, I, p. I94-2I3.

Harmetz, Aljean. (2002). The making of Casablanca. Bogart, Bergman, and World War II. Nova York: Hyperion.

Hubert, Henri \& Mauss, Marcel. (2005). Sobre o sacrifício. São Paulo: Cosac Naify.

Rosten, Leo C. (I94I). Hollywood. The movie colony, the movie makers. Nova York: Harcourt, Brace and Company.

Schatz, Thomas. (1997). Boom and bust. American cinema in the I940s. Berkeley: University of California Press.

Schatz, Thomas. (I99I). O gênio do sistema. A era dos estúdios em Hollywood. São Paulo: Companhia das Letras.

Sklar, Robert. (1994). Movie-made America. A cultural history of American movies. Nova York: Vintage.

Sklar, Robert. (1992). City boys. Cagney, Bogart, Garfield. Princeton: Princeton University Press.

Sobral, Luís Felipe. (20II). O beijo de Spade: gênero, narrativa, cognição. Mana. Estudos de Antropologia Social, I7/3, p. 625-652.

Sobral, Luís Felipe. (2010). Bogart duplo de Bogart. Pistas da persona cinematográfica de Humphrey Bogart, I94I-I946. Dissertação de Mestrado. PPGAS/Unicamp. 
ARTIGO | LUÍS FELIPE SOBRAL

Sperber, Ann M. \& Lax, Eric. (1997). Bogart. Nova York: William Morrow.

Weber, Max. (I97I). Rejeições religiosas do mundo e suas direções. In: Ensaios de sociologia. Rio de Janeiro: Zahar Editores, p. 37I-4IO.

Xavier, Ismail. (2003). O olhar e a cena. Melodrama, Hollywood, Cinema Novo, Nelson Rodrigues. São Paulo: Cosac Naify. 


\section{BOGART EM CASABLANCA: FORMAS RELIGIOSAS DA VIDA POLÍTICA}

Resumo

A partir de uma cena de Casablanca (I942), este artigo apresenta uma análise da transformação sofrida pela persona cinematográfica de Humphrey Bogart durante a Segunda Guerra Mundial. Sem abrir mão da mediação dramática entre indiferença e vulnerabilidade que a caracteriza, a persona de Bogart abandona a posição individualista orientada por um rígido código moral e se torna um herói disposto a realizar sacrifícios pessoais em nome de uma causa justificada. Esse percurso analítico é empreendido através de um duplo ponto de vista: por um lado, descreve-se como Hollywood modificou seu paradigma narrativo para se adequar às demandas governamentais para o esforço de guerra; por outro, explica-se como o sentido político do filme se vale da apropriação de uma forma religiosa.

\section{BOGART IN CASABLANCA:} THE RELIGIOUS FORMS OF THE POLITICAL LIFE Abstract

From a scene from Casablanca (1942), this article presents an analysis of the transformation undergone by the screen persona of Humphrey Bogart during the Second World War. Without sacrificing the dramatic mediation between indifference and vulnerability that characterizes it, the Bogart persona moves from the individualist position guided by a strict moral code to that of a hero willing to make personal sacrifices on behalf of a good cause. This analytical course is undertaken through a double perspective: on the one hand, it describes how Hollywood changed its narrative paradigm to suit the governmental demands for the war effort; on the other, it explains how the political meaning of the film is supported by the appropriation of a religious form.
Palavras-chave:

Humphrey Bogart

(I899-I957);

Hollywood;

Persona cinematográfica;

Guerra;

Sacrifício.

Keywords:

Humphrey Bogart

(I899-I957);

Hollywood;

Screen persona;

War;

Sacrifice. 